\title{
Relation between Multicultural Education, Sociology, and Indigenous Knowledge
}

\author{
Lumban Arofah \\ Sociology and Anthropology Department \\ Faculty of Teacher Training and Education \\ Universitas Lambung Mangkurat \\ Banjarmasin, Indonesia \\ al_arofah@yahoo.com
}

\begin{abstract}
This article aims to link connection between how multicultural education able to learn by introducing Indigenous Knowledge through Sociology Studies because it is proven that sociology is a subject that enabling the student to have the knowledge, attitude, and affective as a social human life. In several education phases, sociology contains several sub-themes that associated with multicultural education. One of paradigm and perspectives that enable the teacher to develop the model of education which more emphasized to local context is indigenous knowledge. This article aims to give example how multicultural education can undergo beyond indigenous knowledge especially in South Kalimantan province which has multicultural areas. This article aims to contribute to the concept of teaching multicultural education in multicultural societies by enabling indigenous knowledge and describe the indigenous knowledge of South Kalimantan Province and how it will able to contribute to multicultural education through Sociology Subject. Several indigenous knowledge of societies contains a value to support multicultural education. This article gives an example of several indigenous knowledge that used by the teacher to promote multicultural education that furthermore will support the development of multicultural societies.
\end{abstract}

Keywords-component; Multicultural Education, Ethno Pedagogy.

\section{INTRODUCTION}

Since the Government of Indonesia issued Act No 20 of 2003 on National Education System, the government develops the idea to increase the quality of Indonesian Education through several steps. The government under The Ministry of National Education then published National Standard of Indonesian Education. There are 8 standards of Indonesian Education Standard which are: Graduate competence standard, Content standards, Standard process, Education Standards and Education Personnel, Infrastructure Standards, Management standards, Standards Education Funding, Education Assessment Standards. To ensure the development of the standard, the Ministry then decided to set mechanism of National Exam for Student in all stages; from Elementary School, Junior Highs School, and High School.

A National Exam becomes an instrument to evaluate the education outcome and developed as an instrument to monitoring a progress and mapping the quality of any disciplines. The National Exam measured the learning aspects such as cognitive, psychomotor, and affective aspect on all disciplines. The government believes the standard will be using the quality of Indonesian student to compete internationally with other students from all around the world.

The National Exam has been operated for 15th years. Apparently, the national exam has been a success to inform the Indonesian education mapping, although there is a disappointment in the uneven result on several regions. On the daily life, it can be seen that the result of the national exam does not show the goal of Indonesian education. In daily behavior, Student often still causes public discontent. There are conflicts among students who making mass struggle in public areas. In other sides, on the job market, the graduates do not show the ability to compete. On the other hand, the business community looked at the graduates do not have a good job readiness. There also dissatisfaction with the graduates at every level of education. The primary school graduates are still not sufficiently equipped to enter secondary schools, while the junior high school graduates are not enough ability to follow high school, furthermore, the high school graduates deemed not enough to enter college.

This research tried to focusing on Sociology discipline since the newly 2013 Indonesian education curriculum gave the mandate to Sociology to develop cognitive, psychomotor, and affective aspect through the standard mechanism systems. According to standard competence in article 3.4, Sociology should give student and ability to describe the process of internalization of the values and norms as forming the personality and the foundation to develop harmonious social interaction. The strengthening point of standard competence is the idea that Sociology is not only about a cognitive matter which required the student to have gradual comprehension about Sociology as a science such as definition, theory, paradigm, characteristic, and methodology, but also drive the student to psychomotor and affective matter. The sociology has also responsible to develop the student as social beings. If there are juvenile delinquency such as mass struggle, drug addiction, and other deviant behavior, Sociology takes its 
responsibility to put the student into social order and develop harmonious interaction with other students.

In South Kalimantan, based on National Exam results on 2014/2015, Sociology is a subject that categorized at C or a middle end with an average point in 61.77 . the range of values between 60 - and 70 is gained only for $25 \%$ of the student.

The unsatisfaction of education quality just like mentioned above is derived from several factors both of internal and external. There are causing factors that made the student is not able to achieve proper results. As an external factor, the students have to deal with the family environment such as the facility to study at home and capability to fund the education. The external factor cannot be measured by coaching, training, or seminar.

This article aims to map the ability student to understand the standard competency of Sociology, figure out the learning material that corresponds to the student characteristic, and develop alternative learning model that able to increase the understanding of standard competence.

\section{METHOD}

The research was undertaken several methodological phases. In the first phase, mapping the understanding of standard competencies for sociology tested at the National Exam. This activity will be obtained maps competence of learners from high school in every subject and competence achievement profile high school students for each subject. Base on the mapping the standard competencies, the research chose several schools; Danau Panggang High School, 2nd Hulu Sungai Tengah School, 2nd Tanjung High School, and 1st Kelua High School.

The second phase of research is identifying the causes that contribute to decreasing factor of understanding sociology standard competency. At this phase, the method used is through the in-depth interview and focus group discussion with a group of student and teacher.

Third phase research is developing suggestion to cover the need for research and material that correspondent to the need of student and teacher. The method and material learning will be drawn by considering the local characteristic especially the geographical and social characteristic at South Kalimantan. By addressing the local context, the learning process will be directly involving the learning goal and the student will understand their social environment gradually.

\section{RESULT AND DISCUSSION}

At the first stage, there were several selected interview with students and teachers of Sociology. Students were chosen from 10th, 11th, and 12th grade in each school picked up by looking their rank in the class and assessments. The student was asked about how they feeling about learning sociology, how the lesson by the teacher, and what the hardest things in learning Sociology.

The interview found that there are diversity student answer and respond. The student from 10th has difficulty in understanding the notion and definition of Sociology from various scholars. We understand that there are several notions in Sociology from theory to other issues. The student faced the difficulty when they examined the exam from classroom exam into the national exam. Students feel confusing in remembering the definition precisely exact words by words.

The teacher has difficulty in teaching Social Research Method. The teacher has difficulty in teaching and explaining Qualitative and Quantitative Research Method. Several issues, such as; Population, Sample, Variable, and Indicator, are difficult to be explained due to time limitation because that competence standard gave at the end of the semester.

The second difficult issue that was difficult to learn and to teach on the standard competence of sociology is "the connection between personality and societal culture". According to the document of National Education Standard, it is clearly stated that that standard competence is to give a student the broader perspective on the diversity of Indonesian inhabitants. This Sub-theme explains the diversity of Indonesian Inhabitant and how the diversity effect to the relation between people.

Both student and teacher have difficulty in relating the theme in standard competence with everyday phenomena. It happened due to the newly 2013 curriculum. This curriculum required the teacher and student to develop learning material method that stimulated the student to bring a project in hand. This method was named by project-based learning that was introduced together with 2013th Newly Curriculum.

\section{A. Newly Curriculum and Project Based Learning}

Education in Indonesia has been facing a new challenge since the Ministry of Education and Culture Republic of Indonesia introduce the 2013 Curriculum and replaced the old KTSP-Kurikulum Tingkat Satuan Pendidikan (School-Based Curriculum Development-SCBD) Curriculum. There are several differences with the previous curriculum in the form of Philosophical Background, Mindset Change, Subject, Orientation and Student assessment.

The Newly Curriculum tried to give broader experience depending on previous KTSP curriculum. The ministry found that in the previous curriculum the goal of competence in attitude, knowledge, and skill was not clearly identified. The previous curriculum was only explained into three separated domain; cognitive, affective, and psychomotor. Unfortunately, in the previous curriculum, the teacher and education component took too much stressed into knowledge domain. Those curriculum strategies will leave behind the importance of affect and psychomotor sides. The assessment was tending to test the student knowledge so do the student report. A study from [1] found that the teacher shows a traditional view of learning with clearly seen as emphasizing the teacher as a center. Limited practice and lack of professional development career of teaching made teacher have no ability to adapt to the implementation of KTSP Curriculum.

Taking a lesson from the previous KTSP Development, the Ministry tried to develop a new curriculum that covers all three domain; Knowledge, Attitude, and Skill. In newly curriculum, a ministry designed the curriculum that covering the religious attitude, knowledge, and skills. Moreover, those 
domains will be written in learning material and tested into student examination. The assessments will explore not only an ability of student knowledge but also base on student performance in creating portfolios, observation report, and attitude assessment.

The differences between curriculums also found in the formation of the subject. For elementary school, the ministry implements a thematic learning material which pursued developing integration between subjects. Moreover, to strengthen the idea, the curriculum introduces scientific paradigm to cover student learning experience in assessing the education domain from religious attitude, skill, and affective.

The idea of implementing newly 2013 curriculum was enriched with a various teaching method that was introduced to the teacher. There are issues on ability teacher adapt with new teaching method because 2013 curriculum forced the student to implement learning model that emphasized student as a learning center. The teaching model was named by Project Based Learning (PBL)

Project Based Learning (PBL) required the teacher to develop task and assignment to student base on the subject that was discussed in the classroom. PBL is a teaching method that trying to defining the problem as important preliminary steps in discussing and integrating a newly knowledge reflecting student ideas [2].

PBL will help teacher and student. The teacher will construct of understanding upon issues which will help them to prepare for other upcoming problem. For the student, they will be able to find the central issues and problem. This skill and process are vital in developing their perspective in constructing knowledge [3].

The PBL implementation needs a scientific approach to learning guidelines. Sometimes science enriched with several biases, rumor, mite, an assumption. The scientific approach stimulates the student to have critical and analytical thinking and attitude that used to have their own view on problemsolving and implementing in learning material. Steps of scientific approach can be drawn into several phases; Observing, Questioning, Associating, Experimenting, and Networking.

\section{B. Teacher Challenge in Teaching Multicultural Education}

As mentioned above, the teacher and student have difficulty in learning the standard competency in "The connection between personality and societal culture". Both of them have difficulty to relate the standard of competency in everyday life. This was held on Project Base Learning issue which was required by the 2013 Curriculum. The difficulty can be seen from several factors.

\section{Monoculture.}

Majority students are affiliated with major ethnic of Banjarnese in South Kalimantan. Although they were experienced connecting with other people with a varied background, those people able to communicate and interact with Banjarnese people with Banjarnese Language.

\section{Comfortability to adapt to Banjarnese Culture}

In South Kalimantan, there are several ethnicities that living in several areas as result of Transmigration program and as well Migration. They were usually living together in several areas, especially in agricultural areas. Although they were maintaining their original culture, they were able to adapt to Banjarnese values and able to communicate with Banjarnese Language. This condition somehow made difficulty for teacher and student. It is because they feel that people that are living around them are similar in everyday life with the student. That condition sometimes made teacher has difficulty to constructing an example for the student to illustrate the issues.

According to from the document from [4], The standard competency of "The connection between personality and societal culture" is drawing into two sub-themes: giving positively respond to the national problem according to social and cultural diversity in society and describe process of value and norms internalization to developing personality and foundation to develop harmonious social interaction.

The sub-themes above are closely related to Multicultural Education. If teacher could not able to clearly explain the subtheme, it will lead to failure in learning multicultural education and it will decrease the ability to student and teacher to develop awareness for those who have different background

Multiculturalism is a condition where inhabitant consists of several people with coming from various backgrounds such as race, ethnicity, and socioeconomic status. Multicultural will lead to decrease the feeling of chauvinism in the community. It is known that differences such as ethnicity and race are existing in societies, we could not able to deny it. However, if we are able to properly manage the differences, the differences will turn into enriching the social and cultural interaction among inhabitant and people in the particular areas.

To promote the idea of multicultural, it is a necessity to develop Multicultural Education. Education is a tool for learning behavior providing from childhood to elderly, multicultural education is important to be promoted from childhood to ensure them to understand the diversity and useful for their future education and life experience. Ref [5] believe that school and communities are the preliminary places to promote multicultural education although they were living in rural areas that usually monoculture. Multicultural education is important for widespread the idea of diversity among inhabitant.

Multicultural Education will be reached it succeeds if they able to promote their diversity to the community outside the school. The multicultural education will be more important if they not only addressing the multicultural education through guideline and curriculum with more deepen in proper learning material but also widespread their idea by undertaking the community resources.

The multicultural education will be successes if they able to take local phenomena such as local value, norms, and social order that tend to promote multicultural education. This goal of this idea is to eliminate cultural and racial barrier. By enabling the childhood multicultural education, they will be 
able to familiarize them self with cultural differences and understand their civil consciousness and support effort of egalitarian democratic culture.

Ref [6] argue that several country and states do not familiarize with multicultural education. There is no policy on maintaining change on the social landscape is blamed the cause of lack understanding of multicultural education. There is a gap between the traditional view of cultural and newly multicultural phenomena made there is no public policy to deal with those gaps. To deal with that situation, Bennett argues that school is important to be the answer to the problem by decrease the gap between traditional view and newly multicultural phenomena.

Developing the multicultural education is complex work by the teacher, student, and school environment. There is 5 dimension of multicultural education:

1. Content Integration.

Teachers are pursued to deals with various cultures in their teaching and construct it as an example and content. The teacher should strengthen them self with various knowledge in culture and phenomena regarding cultural differences matters.

2. Knowledge Construction.

Teacher gives an assistance student to understand, investigate, and determine the cultural assumption, biases, and perspective in which the knowledge is constructed.

3. Prejudice Reduction.

A teacher by curriculum and teaching method focuses to understand student racial attitude and modify it into better understanding in multicultural education.

4. Empowering School Culture.

Creating school culture are developed by enabling interaction between Student, Teacher, and other staff which creating school event, sports participation and other occasions.

5. Equity Pedagogy.

Teacher modify their teaching method and material in which facilitate an academic achievement the student from various racial, cultural, gender, and social-class groups.

Multiculturalism is closely related to pluralism that treats an equal society who have diverse culture and belief to giving respect a human dignity. To strengthening the importance of Multiculturalism, [5] develop a cluster of research in multicultural education.

The first cluster is curriculum research. It is based on an assumption that people will get a constructed knowledge from a historical perspective. The assumption leads genre in multicultural education in genres of Historical inquiry, identify the bias in learning material, and curriculum theory.

The second cluster is equity pedagogy. It is based on the assumption that all children have right to expand their potential talent so the cultural environment should able to increase their talent. This assumption leads a multicultural research which genres: school and classmate research, student achievement, and cultural styles.

The third cluster is a multicultural assumption. This assumption based on the fact that a necessity to decrease racial and cultural prejudice and support an individual to be a multicultural person.
The fourth cluster is societal equity. It is based on the assumption that social change is possible to do equitable access to education to get exact participation. This assumption leads a multicultural research genre: demographic, cultural race in popular culture, and social action.

Multicultural education is a set pattern of learning undertaken by teachers and schools in order to create a student that aware of the social diversity of culture in their everyday life. In such cases, Sociology is one of the subjects that able to promote multiculturalism education in schools. Besides, teaching students' cognitive through debriefing knowledge; history Sociology, Sociological Theory, Sociology approach and methodology Sociology, sociology subjects also had a hidden curriculum to teaches students to have a form of social empathy, social sympathy, and social attitudes toward others who have different backgrounds.

\section{E. Teaching Multicultural Education Through Ethno Pedagogy}

It is mentioned above that Teacher has difficulty to teach Multicultural Education. This article aims to suggest teacher teach multicultural education with Ethno Pedagogy approach. Ethno pedagogy is an activity of cross-cultural teaching method with emphasized in an effort to attaching cultural phenomena into pedagogical studies, hence the modification on cultural and learning material is demanding [6]. With anthropological theories, ethnic pedagogy will able to the understanding learning process in the everyday classroom. All students with various backgrounds such as ethnicity, race, gender, and socioeconomic status will be valued by framework from the teacher. Ref [7] believe that ethnic pedagogy is useful in introducing the cultural pluralism with valued environment around school, teacher, and communities. Burger introduces "applied education ethnology" as a key element of Ethno Pedagogy with ethnic variables such as; cognitive, affective, psychomotor, communication, timing, space, examination, ethics, causality, sociological environment, teaching method, curriculum, and subject matter.

The locality of culture is a key element of ethno pedagogy. The more local culture studied the more ethno pedagogy enriched. Ref [8] who studied Balinese Gamelan, looked ethno pedagogy in perceiving cultural contextualized. Hall noted that traditional music has differed from one place to another. Therefore it is reflecting the variation of characteristic and meaning local values. To strengthening the idea of ethnopedagogy, [9] suggest that ethno-pedagogy should underpin visual and technological learning such as; ethno-pedagogy printed material, visual teaching aid, toys, and video cassettes.

South Kalimantan is an area that categorized by multicultural areas. There are Banjarnese and Dayaknese as indigenous ethnic where Banjarnese as major ethnic. There are also several ethnics as a consequence of migration as well as transmigration government programs, such as Javanese and Balinese. South Kalimantan is geographically wetland areas with several huge rivers. Rivers are an important part because it has social, cultural, economic and transportation function. For economic function, [10] illustrated floating market as an 
economic function of the river. People who sell the good in floating market are usually farmers that live around the river. Floating market only operated in the morning. The operation of the market depends on river and climate. A trader cannot sell the good if there is the bad weather because their boat will carry out by the wind. The lengths of river depend on river stream. The market only operated if the river stream getting slow and smooth.

This condition makes Banjarnese as major ethnic valued this geographical area in their ethnic values. We found several mites, idiom, song, and ethical values that base on river culture. Hopefully teacher able to identify Banjarnese ethic value as an ethno pedagogy and indigenous knowledge the strengthening the multicultural.

There are several Banjarnese ethical values that support the multicultural education. In Banjarnese, there is a popular idiom that was understood and tough by a parent to their kid. This idiom is "Kayuh Baimbai". This idiom was resembled by paddling boat together. This is a famous idiom for Banjarnese which has to mean that all inhabitants should be living in harmony. It is concluded that by leaving behind the differences, all of the inhabitant, people, and society are able to live together and harmony. The teacher can able to use this value as a tool for the student to appreciate the differences and live harmoniously with people that coming from the different background.

In Banjarnese, there is a song that illustrated the indigenous work of Banjarnese. The title of the song is Pembatangan. This song told about the indigenous work of Banjarnese who sell the wood by carrying across headwaters to estuary alongside the Barito River as a major river in South Kalimantan and usually used for transportation matter. The work of carrying wood across the river could be finished by cooperation among worker. Without cooperation, it is impossible to finish the job.

The teacher illustrated the song and asked the student to develop harmonious live with inhabitant surrounding them in their daily life. Society will be able to live together when they were expanding their life by cooperation with other people from various backgrounds. Appreciate the differences and could not be a barrier to maintain cooperation between a student with other student and as well as societies.

\section{CONCLUSION}

Ministry of National Education has been developing a new curriculum that named by the 2013th curriculum. The new curriculum is enabled the teacher to develop the learning mechanism which able to increase the curiosity of pupils. One of learning paradigm is ethno pedagogy. The ethno pedagogy is a system that enables pupils to interact with the more cultural context of society.

\section{REFERENCES}

[1] Sulfsyah, Investigating the Implementation of the Indonesian KTSP (School-Based Curriculum) in the Teaching of Writing in Year Two. Unpublished Doctoral Thesis of Edith Cowan University. Australia, 2013.
[2] F. Patrick, and A. McPhee, Evaluating The Use of Problem-Base Learning in New Initial Teacher Education Degree. Teacher Education Advancement, 2014.

[3] Y. Kirgoz, "Designing and Implementing an Innovative Problem-Based Teacher Education Course", American Journal of Educational Science. Vol. 1, No. 5, 2015, 2015, pp. 229-239

[4] Ministry of National Education, Standard Competency for High School and Moslem High School, 2013

[5] L. Nganga, "Multicultural Curriculum in Rural Early Childhood Programs". Journal of Praxis in Multicultural Education, Vol 9, N 1, 2015

[6] C. Bennett, "Genres of Research in Multicultural Education". Journal of Review of Educational Research.; 71, 2001, pp 171.

[7] H.G. Burger, "Ethno-Pedagogy": A Manual in Cultural Sensitivity, with Techniques for Improving Cross-Cultural Teaching by Fitting Ethnic Patterns", ERIC Document Reproduction Service. Maryland, 1968.

[8] P.D. Hall, "Ethnopedagogy: Culturally Contextualised Learning and Teaching as an Agent of Change", The Refereed Journal of the Mayday Group Vol 8. No. 2, 2009.

[9] S.K. Albildina, and N. N. Nietullaeva, "Development Raders Interest of Junior Schoolchildren with Means of Ethnopedagogics", Journal of Education and Science Without Borders. Vol.1 No. 1, 2010

[10] A. Daud, Islam dan Masyarakat Banjar - Islam and Banjarnese Societies. Raja Grafindo Persada, Jakarta, 1997. 